\title{
The Status, Requirements and Suggestions to the Integration of Transportation Network and New Energy Network
}

\author{
Wang Xianguang $^{1 \mathrm{a}}$, Sun Kechao ${ }^{1 \mathrm{~b}}$, Shang Jinping ${ }^{1 \mathrm{c}}$, Liu Zhenguo ${ }^{1 \mathrm{~d}}$ Oscar \\ Wangyihong ${ }^{2 \mathrm{e}}$ \\ ${ }^{1}$ China Academy of Transportation Sciences, China \\ ${ }^{1}$ China Merchants International Technology Company Ltd, China \\ awxgjky@126.com, ${ }^{\mathrm{b}}$ sunkechao2004@163.com, ${ }^{\mathrm{c}}$ 77300580@qq.com, ${ }^{\mathrm{d}}$ liuzg211@qq.com, \\ escarwang@cmhk.com
}

Keywords: Transportation Network, New Energy Network, Integration, Suggestion

\begin{abstract}
Green development is an inevitable requirement for Traffic Development Strategy. The deep integration of Transportation Network(TN) and New Energy Network(NEN) would become the main trend in the future. This article focused on the analysis of the integration development of Road Network, Water Transportation Network with NEN. About TN, it analyzed the status of Road Networks including common national highways and national highways. Also, it analyzed the status of Water Transport Networks including high-grade channel networks, port layouts, and the layout of ports and electricity. About the NET, it analyzed the vehicle sales, construction of charging piles, smart platforms, the layout of ports and electricity and the application status. From the perspective of coordinated development, green transportation, and smart transportation, it analyzed the needs between the TN and NEN. Finally, the suggestions for the development of two-network integration were proposed from the aspects of the deep integration of Road Network and NEN, the deep integration of Water Transportation Network and NEN, and the formulation of standards and the release of indexes.
\end{abstract}

\section{Introduction}

Green development is an inevitable requirement for the Traffic Development Strategy(TDS). The construction of TDS should firmly establish the concept of socialist ecological civilization, and practice of Green Mountain is Jinshan Yinshan, we must promote the application of new energy and clean energy in the transportation industry, optimize transportation energy structure, and reduce the impact of transport activities on environmental factors such as air, water and land. According to the research report of the International Renewable Energy Agency, the wind, electricity, photovoltaic and other new energy sources will be used in large scale in the transportation in future. At present, many domestic scholars on the development of new energy vehicles, the development needs, system design, and established the new transportation energy assessment indexes ${ }^{[1][2][3]}$. Some experts analyzed the problems existing in charging facilities for electric vehicles ${ }^{[4]}$. Some experts analyzed the problems existing in charging facilities for electric vehicles ${ }^{[5][6]}$. However, there is no analysis of the development status and requirements from the perspective of convergence between the two networks. The deep integration of TN and NEN would become the main trend in the future. Promoting the deep integration of TN and NEN has become an inevitable demand for the construction of TDS.

\section{The Status and Planning of TN}

With the development of economic society and infrastructure construction, China has initially formed a multi-node, full-coverage integrated transportation network.From the layout of the road network, National highway total mileage 4,773,500 kilometers, and the density 49.72 kilometers / hundred square kilometers at the end of 2017. According to "National Highway Network Planning 
(2013-2030)", the road network planning will reach 401,000 kilometers. Where, the general national network consists of 12 capital cities, 47 north-south vertical lines, 60 east-west horizontal lines, and 81 tielines, with a total size of approximately 265,000 kilometers. The national highway network consists of 7 capital cities, 11 north-south vertical lines, and 18 east-west horizontal lines, as well as regional loops, parallel lines, and tie lines, and approximately 118,000 kilometers, the long-term prospect line is 18,000 kilometers $^{[7]}$.

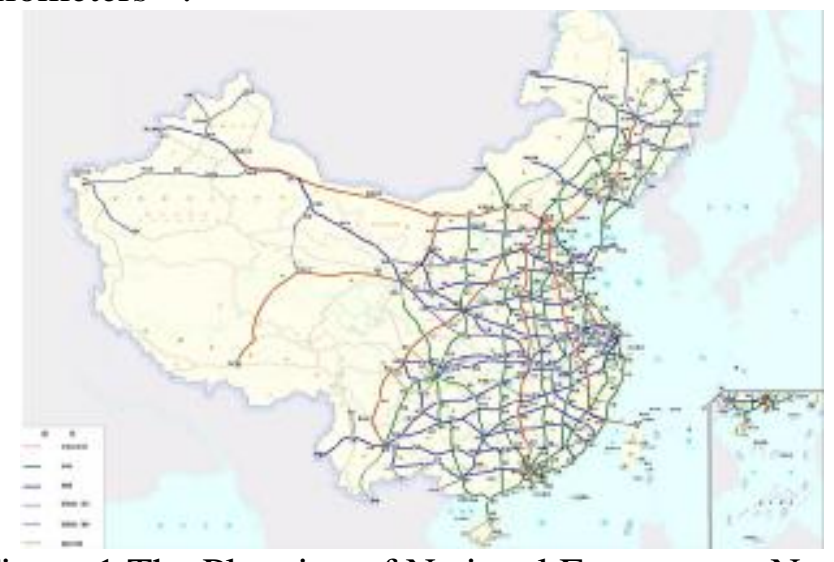

Figure 1 The Planning of National Expressway Network

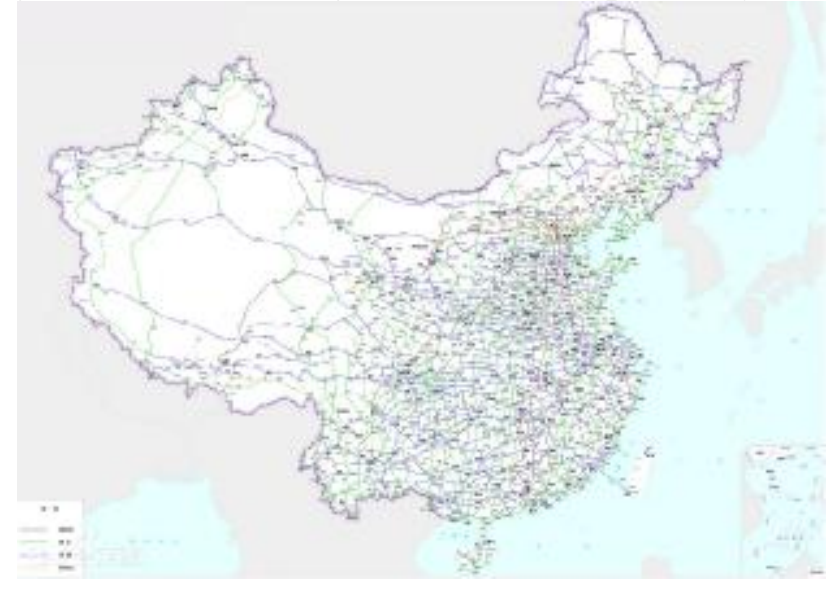

Figure 2 The Planning of Ordinary National Road in China

From the perspective of Water Transport Network layout, the total mileage of China's inland waterways is 127,000 kilometers at the end of 2017, where, the level 2 and above navigable routes 125000 kilometers, 4th-level fairways 10781 kilometers. There are 27,578 berths for production in the country, where, 5830 berths for production of coastal ports and 21748 berths for production of Inland port. According to the National Inland Waterway and Port Layout Planning (2006-2020), It plans to form about $19,000 \mathrm{~km}$ of high-grade inland waterways, forming a high-grade channel network (referred to as 2-1-2-18) and 28 major port layouts of "two horizontal, one vertical, two networks and eighteen lines". According to the "port and shore electricity layout plan", More than $50 \%$ of the ports in major ports and ship emission control areas in the country have built containers, passenger rolling, cruise ships, passenger transport of over 3,000 tons, and specialized berths of dry bulk cargo of over 50,000 tons. The company has the ability to supply shore power to ships by the end of 2020. There are 493 specialized berths capable of supplying shore power to ships in ports in major ports and ship emission control areas across the country ${ }^{[7]}$. 


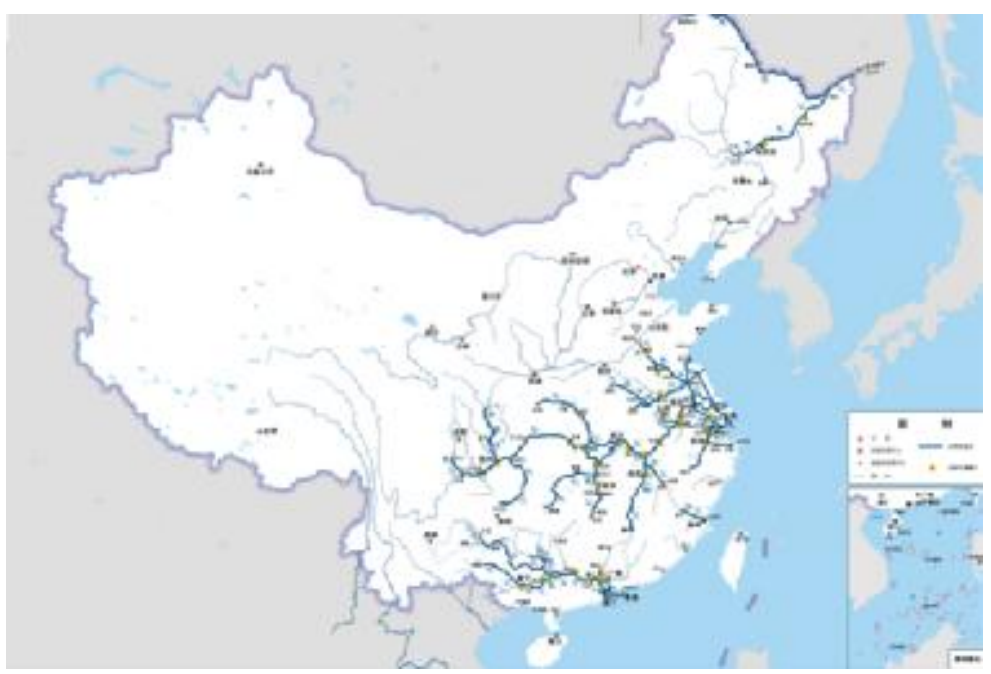

Figure 3 The layout of high-grade channels and major ports in China

\section{The Status of NEN in Transportation}

The application of new energy in the field of transportation develops rapidly in recent years. In vehicle sales, According to statistics from China Association of Automobile Manufacturers, the production and sales of new energy vehicles were 774,000 units and 777,000 units respectively in 2017, where the sales of pure electric vehicles accounted for $84 \%$ (60\% for pure electric passenger cars and $24 \%$ for pure electric commercial vehicles). In charging, pile construction, the charging capacity reached 2.30 billion $\mathrm{kwh}$, charging 57 million times in 2017 . The operators have built 169,000 charging piles, of which 123,000 are operated by the society, and 46,000 are self-supported by the State Grid. It has initially formed a "nine vertical and nine horizontal two rings" high speed intercity fast charge network, covering 19 provinces and 150 cities with mileage exceeding 31,000 kilometers.

In terms of smart platform construction, it has initially built a smart car networking cloud platform. The platform has accumulated a total of more than 168,000 access charging piles. Relying on smart car networking platform, 17 charging operators realize interconnection. The total number of charging piles connected to the car networking platform exceeds 168,000. It initially formed a national network of NEN.

In terms of port layout, the State Grid's port shore electricity has covered 15 provinces across the country, forming a "two vertical and one horizontal" pattern of the eastern coastal port, the Beijing-Hangzhou Grand Canal port and the port along the Yangtze River.

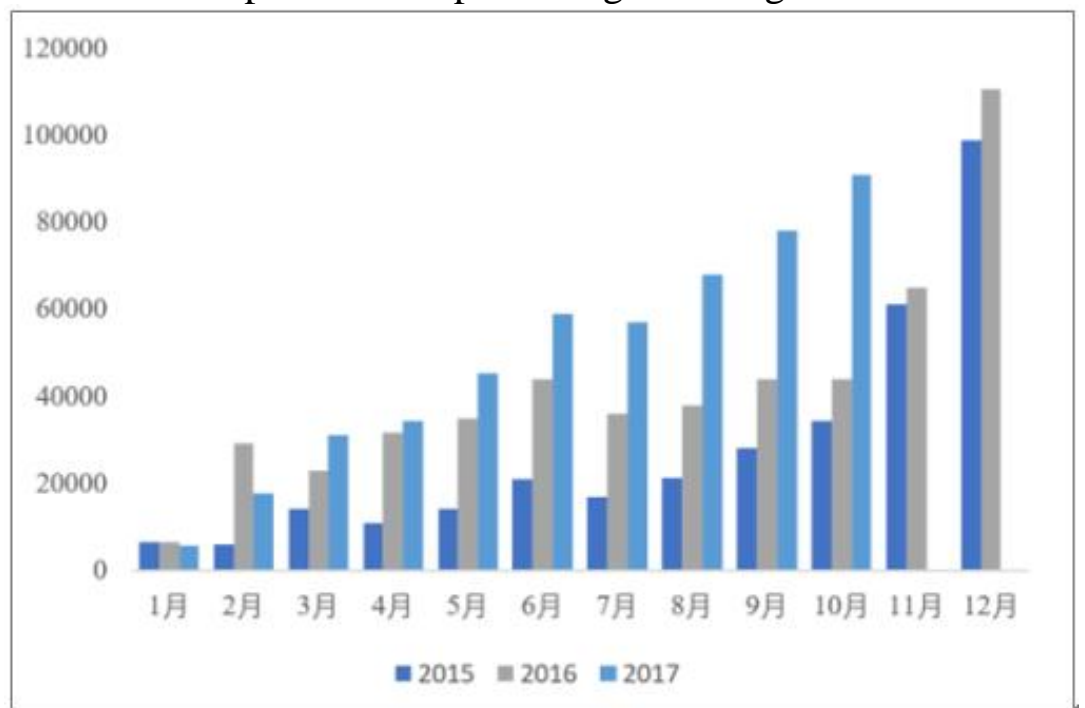

Figure 4 Monthly sales of new energy vehicles in 2015-2017 (units) in China 


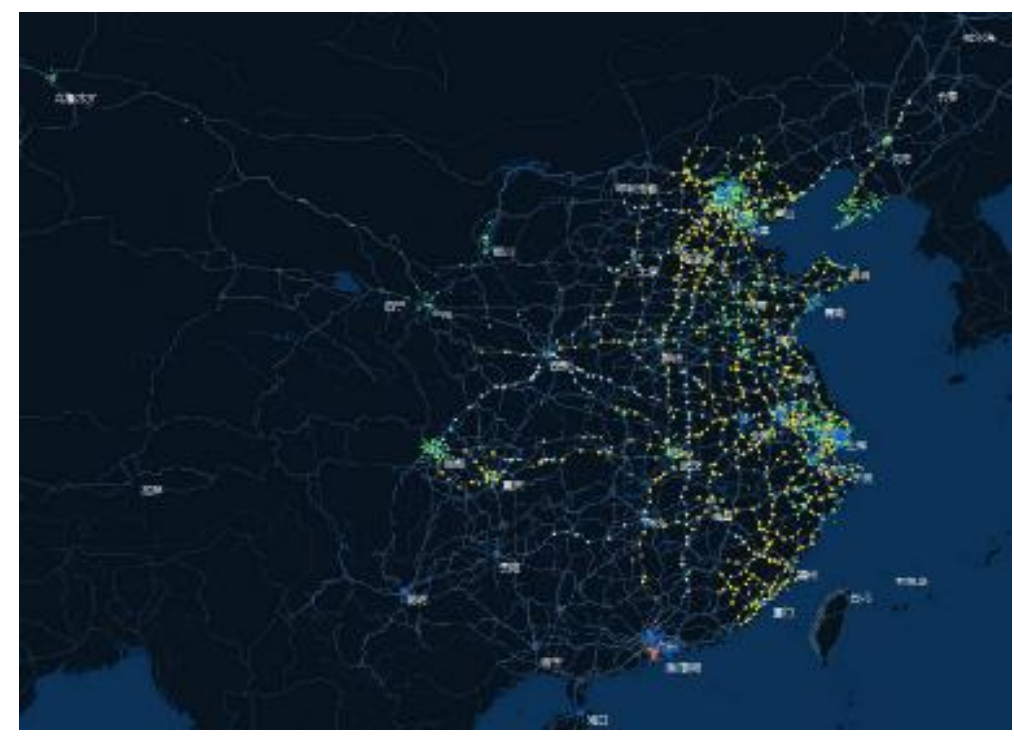

Figure 5 The layout of charging pile status in China

\section{Analysis of the Requirements to the Integration of TN and NEN}

\section{(I) It is the requirements to Coordinated Development.}

Infrastructure construction of TN and NEN is the engine to promote economic and economic development, it is also the important basic condition for economic and social development. Since the reform and opening up, "transport network" and "new energy network" have achieved a leap-forward development, and the volume and scale have leapt to the top of the world. However, due to the influence of traditional energy consumption structure, the integration of the two networks has not been considered for a long time, the insufficient consideration in many aspects such as planning, design, operation, etc. During the construction of the highway network, the planning, design and operation of the highway network mainly focus on the use of traditional "fuel vehicles", lacking of synchronous planning for charging facilities. Similarly, during the construction of the national grid, Followed the principle of parallel with the traffic network in the circuit planning and design, mainly in the transmission of electricity, however, there are insufficient considerations in the layout of facilities such as expressway service areas, tunnels, general provincial car parks, toll stations, and port shore power facilities.

(II) It is the requirements to Green Development.

Building Ecological Civilization is a Thousand Year Plan for Sustainable Development of the Chinese Nation. Deeply promote the development of green transportation and become an important aspect of economic and social development. According to China's new energy vehicle development plan, the electric vehicle inventory will reach 5 million by 2020, and exceed 50 million by 2030, Occupy the car market sales will reach $5 \%$ and $30 \%$ respectively. The rapid growth of electric vehicle ownership poses a strong demand for green energy comprehensive services. In reality, solving the core problem of electric vehicles is not just battery life, the provision of clean electricity supply services in ports, highway service areas, tunnels, toll stations, parking lots, etc. It should make full use of the use of highway slopes, service areas, idle land along the line and toll station service area roof resources, building a green energy integrated service system integrating distributed photovoltaic and storage and charging, giving clean energy services and comprehensive support for port terminals, ships, new energy vehicles and smart highway service facilities.

\section{(III) It is the requirements to Intelligent Transport System.}

The trend of deep integration of new generation information technology and transportation is increasingly evident, the construction of smart transportation will increase a lot of information facilities. Especially with the wide application of 5G technology, the use of DSRC roadside equipment, WIFI equipment, microwave detection equipment, Beidou positioning ground station, etc. will greatly increase the use of electricity demand. Using traditional power supply methods will 
inevitably lead to increased energy waste and carbon emissions. Therefore, it is necessary to Building smart road network and developing smart traffic must be deeply integrated with clean energy with the new generation of national traffic control network and smart highway pilot work and Smart Port Demonstration Project advancing by the Ministry of Transport. Promoting the integration of TN and NEN has become a basic condition for the development of ITS.

\section{(IV) It is the requirements to the policy.}

In 2012 and 2014, the State Council successively issued the "Energy-saving and New Energy Vehicle Industry Development Plan (2012-2020)" (GF [2012] No. 22) and the "Guideline for Accelerating the Popularization and Application of New Energy Vehicles by the General Office of the State Council” 》([2014] No. 35). In order to implement the spirit of the relevant documents of the State Council, the Ministry of Transport has issued several policy documents one after another. Among them, the "Implementation Opinions of the Ministry of Transport on Accelerating the Promotion and Application of New Energy Vehicles in the Field of Transportation and Transportation" ([2015] No. 34) it states that, by 2020, the application of new energy vehicles in the transportation industry will begin to take shape. The supporting service facilities for new energy vehicles will be basically complete, and the operational efficiency and safety level of new energy vehicles will be significantly improved. In the "Notice of the 13th Five-Year Development Plan for Transport Energy Conservation and Environmental Protection" ([2016] No. 94), it states that: Encourage the application of clean energy such as solar energy and wind energy, as well as the use of charging and replacement facilities in transportation infrastructure construction operations. In the "Guiding Opinions on the Implementation of Green Highway Construction" ([2016] No. 93), it states that: promote the application of solar energy, wind energy, geothermal energy, natural gas and other clean energy applications according to local conditions. "Opinions of the Ministry of Transport on Comprehensively Deepening the Development of Green Transportation" ([2017] No. 186), it states that: Strengthen the research and development of green transportation technology and obtain a number of breakthrough scientific research achievements in areas such as highway power generation as soon as possible. The number of new energy and clean energy vehicles in the transportation industry will reach $600,000, \mathrm{CO} 2$ emission intensity of transportation will decrease by $7 \%$ over 2015 , by 2020. The National Development and Reform Commission issued the "Guidelines for the Development of Electric Vehicle Charging Infrastructure (2015-2020)" and "The 13th Five-Year Plan for Power Development (2016-2020)", it states that:by 2020, cumulative photovoltaic installed capacity will be $60 \mathrm{GW}$, and increase the number of centralized charging and recharging stations by more than 12,000 and distributed decentralized charging piles by more than 4.8 million. In summary, the promotion of the integration of the two networks already has the basis for various policy measures. In summary, the promotion of convergence between the two networks already has various policy foundations and needs.

\section{The Suggestions to the Integration of TN and NEN.}

\section{(I) Promoting the deep integration of the Road Network and NEN}

The first is to build a batch of optical storage and integrated integrated energy stations. Basing on the integration of the flexible resources of photovoltaic, energy storage, charging and other power grids, establish an integrated energy station at the highway service area, expressway slope protection, toll stations, and parking lots, etc. Utilize the interactive capabilities of smart car networking platform and power grid to improve the reliability of grid operation, improve reliability of grid operation and reduce grid construction costs, provide clean energy services for people traveling.

The second is to carry out V2G (car network interaction) research and pilot work. New Energy Intelligent Charging Parking Lot Combined with Highway Network Construction. Trial electric vehicles as terminal discharge and auxiliary service subsidies and realize the cooperative layout of photovoltaic and electric vehicles. Encourage electric vehicles to participate in peak-to-peak frequency regulation, peak-shaving and valley-filling services in the grid according to their needs. 
The third is to carry out layout planning for highway network charging and power exchange service facilities. Accelerate the deep integration of the national expressway network and the intercity fast charging network. Improving the layout plan of highway network charging service facilities.

\section{(II) Promoting the deep integration of the Water Transport Network and NEN}

The first is to build the Port and Shore Power Network. Combined with the "Port and Shore Power Distribution Plan" promulgated by the Ministry of Transport, built coastal, Grand Canal, and Yangtze River "two vertical and one horizontal" port shore power systems gradually. Achieve the full coverage of the port, rivers, lakes and seas, reduce environmental pollution at port terminals, create "green cycle low-carbon ports". Establish a market-based cooperation mechanism for mutual benefit and win-win between power grids, ports and ships, solve the problems of low applicability, poor reliability and low utilization rate of the port shore electricity system, support the development of green shipping interconnection.

The second is to promote the demonstration project. Promote demonstration projects such as the transformation of oil from green ports, container docks to shoreline, use of shore power by ships in Hong Kong, and inland water LNG power ships.

\section{(III) Research on the relevant standards and index release.}

The first is to carry out relevant standards research. Research on the energy implementation standards in the construction of transportation networks, and the standard of road network supporting facilities in clean energy projects. Accelerate the development of charging and replacement service facility configuration guidelines for highways, common state highways, general passenger hubs, logistics parks, port terminals and other applications. Research on light pollution, shelter forest shielding and other components of highways

The second is the release of the electric vehicle industry development index. Through the analysis of a large number of vehicle travel data, formulate electric vehicle development index, representing the development status and trends of the electric vehicle industry, provide scientific and quantifiable basis for the government and industry decisions.

\section{Acknowledgements}

This work was financially supported by State Grid Electric Vehicle Service Co., Ltd..

\section{References}

[1] LV Ying, CHEN Xiao-hong, YE Jian-hong. Transportation System Design of New Energy Vehicles Based on Trip Characteristics. TRAFFIC \& TRANSPORTATION. 2010 (2) :32-35.

[2] Hou Ronghua, Xu Rongrong. Research on new transportation energy assessment indexes. 2010 , 05 (10): :784-788.

[3] Shen Lon-li. Sustainable Transportation Strategy against Energy Insufficiency and Environmental Needs. URBAN TRANSPORT OF CHINA. 2008 , 6 (4) :12-15.

[4] X.D. Li, ENERGY OF CHINA. Present situation of new energy automobile development and application prospect. $2009,31(8): 43-45$.

[5] FAN Yong-gen, QIAN Wei-zhong. Discussion on the Planning and Construction of Charging Facilities for Electric Vehicles. EAST CHINA ELECTRIC POWER. 2010, 38 (11) :1671-1674

[6] Xiao Xiangning, Wen Jianfeng, Tao Shun, Li Qiushuo. Study and Recommendations of the Key Issues in Planning of Electric Vehicles' Charging Facilities. Transactions of China Electrotechnical Society. 2014, 29 (8) :1-10.

[7] Information on http://www.mot.gov.cn/ 